\title{
Pemberdayaan Ekonomi Masyarakat Desa Padamulya Melalui Pendirian Baitul Maal Wa Tamwil
}

\section{Economic Empowerment of Padamulya Village Through Establishment of Baitul Maal Wa Tamwil}

\author{
Rangga Ardiansyah ${ }^{1}$, M. Komarudin ${ }^{2}$ \\ ${ }^{1}$ Program Studi Ekonomi Syariah Fakultas Ekonomi Islam Universitas Djuanda Bogor, Jl Tol Ciawi No.1, \\ Kotak Pos 35 Bogor 16720, e-mail: ranggaardiansyah028@gmail.com \\ ${ }^{2}$ Program Studi Perbankan Syariah Fakultas Ekonomi Islam Universitas Djuanda Bogor, Jl Tol Ciawi No.1, \\ Kotak Pos 35 Bogor 16720, e-mail: m.komarudin@unida.ac.id
}

(Diterima: 25-06-2020; Ditelaah: 25-09-2020; Disetujui: 10-02-2021)

\begin{abstract}
Abstrak
Inisiasi pendirian Lembaga Keuangan Mikro Syariah merupakan kegiatan dalam memperkenalkan sistem ekonomi syariah kepada masyarakat. Metode pelaksanaan dalam inisiasi pendirian Lembaga Keuangan Mikro Syariah adalah survey lokasi, membentuk tim penanggung jawab, menyusun perencanaan sebagai tahap awal inisiasi pendirian Lembaga Keuangan Mikro Syariah, rapat konsolidasi tim penanggung jawab, dilanjutkan dengan rapat koordinasi dengan aparatur desa menindak lanjuti dari hasil konsep perencanaan inisiasi pendirian Lembaga Keuangan Mikro Syariah.
\end{abstract}

Kata Kunci: BMT, Masyarakat, Pemberdayaan Ekonomi

\begin{abstract}
The initiation of the establishment of a Sharia Microfinance Institution is an activity in introducing the sharia economic system to the public. The implementation method in initiating the establishment of a Sharia Microfinance Institution is a site survey, forming a team in charge, preparing a plan as the initial stage of initiating the establishment of a Sharia Microfinance Institution, a consolidation meeting for the team in charge, followed by a coordination meeting with village officials following up on the results of the initiation planning concept. establishment of Sharia Microfinance Institutions.
\end{abstract}

Keywords: BMT, Society, Economic Empowerment

\section{PENDAHULUAN}

Di Desa Padamulya belum ada Lembaga Keuangan Mikro Syariah (LKMS) seperti Bitul Maal Wat Tamwil (BMT), biasanya Lembaga Keuangan Mikro Syariah berfungsi sebagai lembaga yang menjalankan sistem oprasionalnya sesuai dengan syariat Islam. Oleh karena itu dibutuhkannya sosialisasi kepada masyarakat tentang Lembaga Keuangan Mikro Syariah ini. Tujuan dari di adakannya Lembaga Keuangan Mikro Syariah ini adalah untuk pemberdayaan ekonomi masyarakat Desa Padamulya Kecamatan Pasirkuda Kabupaten Cianjur.

Desa Padamulya terletak diwilayah kecamatan Pasirkuda Kabupaten Cianjur yang merupakan hasil dari pemekaran Desa Girimukti Dusun Cimahpar dan Desa Girijaya Dusun Lingkungsari. Padamulya merupakan desa yang berdiri sejak tahun 2010 yang berasal dari hasil pemekaran 2 (dua) desa, yaitu pemekaran dari Desa Girimukti dan Desa Girijaya. Desa Padamulya menjadi salah desa termuda dari 9 (Sembilan) desa yang ada di wilayah 
Kecamatan Pasirkuda Kabupaten Cianjur. Desa ini memiliki luas wilayah seluruhnya 2.313.373 Ha.

Inisiasi pendirian LKMS merupakan kegiatan dalam memperkenalkan sistem ekonomi syariah kepada masyarakat. Sosialisasi merupakan salah satu cara yang paling tepat untuk memberikan pemahaman kepada masyarakat mengingat pentingnya ekonomi islam untuk dipahami oleh setiap kalangan masyarakat. Oleh karena itu, disinilah peran penting dari sosialisasi ekonomi syariah agar masyarakat bisa mengetahui manfaat dari mengenal ekonomi Syariah.

\section{METODE PELAKSANAAN}

Metode yang digunakan adalah sosialisasi dan inisiasi pendirian Lembaga Keuangan Mikro Syariah. Adapun metode pelaksanaan dalam inisiasi pendirian Lembaga Keuangan Mikro Syariah adalah melakukan survey lokasi, kemudian membentuk tim penanggung jawab, dilanjutkan dengan membuat perencanaan sebagai tahap awal inisiasi pendirian Lembaga Keuangan Mikro Syariah, kemudian mengadakan rapat konsolidasi tim penanggung jawab, dilanjutkan dengan rapat koordinasi dengan aparatur desa menindak lanjuti dari hasil konsep perencanaan inisiasi pendirian Lembaga Keuangan Mikro Syariah, kemudian dilanjutkan pada inisiasi Lembaga Keuangan Mikro Syariah dan dilanjutkan dengan pembentukan pengurus, penyusunan AD ART, sampai kepada pendirian Lembaga Keuangan Mikro Syariah berbentuk Baitul Maal Wat Tamwil (BMT).

Sasaran utama kegiatan ini adalah seluruh masyaraka, agar inisiasi pendirian LKMS bisa bermanfaat bagi seluruh masyarakat yang ada di Desa Padamulya. Program ini dilaksanakan karena masih banyaknya masyarakat yang terjerat dengan pinjaman dari bang keliling. Tujuan dari kegiatan ini adalah untuk saling bertukar pengetahuan seputar ekonomi syariah dan sistem yang ada didalamnya. Oleh karena itu dengan adanya program inisiasi pendirian LKMS ini dapat memberikan dampak positif bagi pengetahuan dan perekonomian masyarakat.

\section{HASIL \& PEMBAHASAN}

BMT atau Baitul Mal wa Tamwil diambil dari dua kata yang berbeda, yaitu: Baitul Maal (rumah uang) dan Baitut Tamwil (rumah pembiayaan). Untuk itu dapat dipahami bahwa BMT merupakan lembaga keuangan syariah yang bersifat sosial dan memiliki dua fungsi, yaitu Baitul Maal (Lembaga Sosial) dan Baitut Tamwil (Lembaga Komersial). Operasional yang dilakukan BMT dari kedua fungsi tersebut adalah sama-sama menghimpun dana dari masyarakat dan menyalurkannya lagi kepada masyarakat, akan tetapi jenis dana yang dihimpun dan disalurkannya berbeda. (Dewi, 2017: 99). Berdasarkan hal tersebut, tim pengabdi mencoba untuk memberdayakan ekonomi masyarakat melalui Pendirian BMT Padamulya.

Program inisiasi pendirian LKMS terdiri dari beberapa tahap, diantaranya: tahap awal, tim pengabdi melakukan perencanaan tentang inisiasi pendirian LKMS yang 
melibatkan pihak-pihak terkait melalui cara diskusi dengan aparatur desa Padamulya. Salah satunya adalah Bapak Parno S.I.P yang merupakan Kepala Desa Padamulya dan Bapak Ikhsan Ginanjar S.EI yang merupakan sekretaris Desa Padamulya. Hal-hal yang dibahas dalam diskusi tersebut diantaranya adalah mahasiswa menawarkan kepada beliau untuk mendirikan LKMS di Desa Padamulya Kecamatan Pasirkuda. Tanggapan atau respon beliau terkait tawaran tersebut cukup baik dan mendukung untuk didirikannya LKMS di Desa Padamulya karena telah adanya keinginan dari pihak desa untuk mendirikan LKMS. Selain itu, hal lain yang dibahas dalam diskusi tersebut adalah bagaimana cara memberikan pemahamankepada masyarakat tentang konsep LKMS yang akan didirikan. Mengingat sebagian besar masyarakat Desa Padamulya belum mengetahui tentang LKMS ataupun lembaga keuangan syariah lainnya. Sehingga dengan pemberian pemahaman kepada masyarakat tentang LKMS, maka masyarakat selain akan mengetahui LKMSyang akan didirikan, juga dapat mendukung dalam operasional yang dilakukan LKMS tersebut. Mahasiswa menindaklanjuti dengan cara membuat materi tentang LKMS dan operasionalnya yang akan disampaikan kepada masyarakat. Sedangkan Bapak Parno S.I.P dan Bapak Ikhsan Ginanjar S.EI menindak lanjuti dengan melakukan koordinasi dengan pihak lainnya untuk mendukung pendirian tersebut.

Pada hari Sabtu tanggal 17 Agustus 2019 dilaksanakan sharing tentang pengalaman dalam pendirian BMT Kabandungan bersama Bapak Saeful Anwar S.EI. Dari sharing tersebut mahasiswa dapat mengetahui gambaran umum dalam mendirikan BMT. Rapat Inisiasi Pendirian LKMS dilaksanakan selamaempat kali, yaitu rapat pertama dilaksanakan pada hariMinggu tanggal 18 Agustus 2019 bersama seluruh mahasiswa kelompok 1, 2, 3, dan 4 di posko KKN kelompok 4 yang membahas tentang perancangan maksud dan tujuan pendirian LKMS.

Rapat kedua dilaksanakan pada hari Rabu tanggal 21 Agustus 2019 bersama aparatur desa yang membahas mengenai pengenalan maksud dan tujuan LKMS. Rapat ketiga dilaksanakan pada hari Sabtu tanggal 24 Agustus 2019 bersama kepala desa dan masyarakat Desa Padamulya di Gedung Dwimulya. Dimana mahasiswa mensosialisasikan tentang pengertian, manfaat, simulasi, contoh sukses BMT Kabandungan, kepengurusan, target yang ingin dicapai, dan struktur LKMS.

Rapat keempat dilaksanakan pada hari Senin tanggal 27 Agustus 2019 yang membahas mengenai pembentukan LKMS. Dari rapat tersebut disepakati akan didirikannya LKMS dalam bentuk BMT, yaitu dengan nama BMT Padamulya serta dirancangnya visi-misi, logo dan struktur kepengurusan. Ketua BMT Padamulya ini adalah Bapak Ikhsan Ginanjar S.EI. Peresmian BMT Padamulya dilaksanakan pada hari Kamis tanggal 5 September 2019 diGedung Dwimulya Desa Padamulya yang diresmikan oleh Kepala Desa Padamulya yaitu Bapak Parno S.I.P dan Ketua BMT Padamulya yaitu Bapak Ikhsan Ginanjar S.EI. 


\section{KESIMPULAN}

Kegiatan yang penulis lakukan berjalan dengan lancar dari perencanaannya, perizinannya hingga waktu pelaksanaannya. Meskipun mendapat hambatan pada saat pelaksanaannya. Namun hal ini tidak membuat penulis membatalkan program Inisiasi Pendirian Lembaga Keuangan Mikro Syariah. Sebagian Masyarakat pun merespon dengan baik kegiatan ini. Dengan diresmikannya BMT Padamulyaini diharapkan dapat meningkatkan kemampuan masyarakat dalam bidang ekonomi syariah sehingga masyarakat dapat mengembangkan potensi ekonomi yang ada di wilayah tersebut.

\section{DAFTAR PUSTAKA}

Ayogi, V. D., \& Kurnia, T. (2015, Juni). Optimalisasi Peran BMT dalam Upaya Penghapusan Praktik Rentenir. Jurnal Syarikah, Vol. 1 No. 1, Pp 1.

Anshori, M. Y. (2018). Laporan Individu Kegiatan Kuliah Kerja Nyata di Desa Cianaga Kec. Kabandungan Kab. Sukabumi.

Buku Pandun Kuliah Kerja Nyata Fakultas Ekonomi Islam Universitas Djuanda Bogor 2019

Dewi,S.H.,M.H, N. (2017, Februari - Juli). Regulasi Keberadaan BMT dalam Sistem Perekonomian di Indonesia. Jurnal Serambi Hukum, Vol. 11 No. 1, Pp. 96-97.

Gayo, A. A., \& Taufik, I. A. (2012, Agustus). Kedudukan Fatwa DSN-MUI dalam Mendorong Perkembangan Bisnis Perbankan Syariah (Perspektif Hukum Perbankan Syariah). Jurnal Rechtsvinding (Media Pembinaan Hukum Nasional), Vol. 1 No. 2, Pp. 262.

Hidayah, A. N., \& Kartini, I. A. (2016). Peranan Bank dalam Sosialisasi dan Edukasi Masyarakat tentang Kemanfaatan Produk dan Jasa Perbankan Syariah. Jurnal Kosmik Hukum, Vol. 16 No. 1, Pp. 75

Jenita. (2017, Desember). Peran Lembaga Keuangan Mikro Syariah dalam Pemberdayaan Ekonomu Masyarakat Kecil Menengah. Jurnal Lembaga Keuangan dan Perbankan, Vol. 2 No. 2, Pp. 3. 